\title{
The differential regulation of microRNAs is associated with oral cancer
}

\author{
SHIH-CHANG TSAI ${ }^{1}$, SHENG-FONG HUANG $^{1}$, JO-HUA CHIANG $^{6}$, YEN-FU CHEN $^{1}$, \\ CHIA-CHANG HUANG ${ }^{2}$, MING-HSUI TSAI ${ }^{2}$, FUU-JEN TSAI ${ }^{3,4}$, MING-CHING KAO ${ }^{1}$ and JAI-SING YANG ${ }^{5}$ \\ ${ }^{1}$ Department of Biological Science and Technology, China Medical University, Taichung; ${ }^{2}$ Department of Otolaryngology, \\ China Medical University Hospital, Taichung; ${ }^{3}$ Human Genetic Center, China Medical University Hospital, Taichung; \\ ${ }^{4}$ School of Post-Baccalaureate Chinese Medicine, China Medical University, Taichung; ${ }^{5}$ Department of Medical \\ Research, China Medical University Hospital, China Medical University, Taichung; ${ }^{6}$ Department of Nursing, \\ Chung-Jen Junior College of Nursing, Health Sciences and Management, Chiayi County, Taiwan, R.O.C.
}

Received February 8, 2017; Accepted July 4, 2017

DOI: $10.3892 /$ or.2017.5811

\begin{abstract}
Oral squamous cell carcinoma (OSCC), is the most frequently occurring malignant head and neck tumor, generally it exhibits a poor prognosis, and metastasis is the main cause of death in these cancer patients. The discovery of reliable prognostic indicators for tumors progression would greatly improve clinical treatments. MicroRNAs (miRNAs) play a critical role in the degradation of mRNA and the inhibition of protein synthesis. The miRNAs function either as tumor suppressors or as oncogenes in tumorigenesis, and little is known about the clinical significance of miRNA expression profiles in oral cancers. In the present study, we investigated the expression profiles of miR-375, miR-204 and miR-196a in 39 healthy and tumor tissue pairs of oral cancer patients using TaqMan real-time quantitative polymerase chain reaction (qPCR). The predicted target genes for miR-375, miR-204 and miR-196a were confirmed using luciferase reporter-based assays and western blot analyses. In oral cancer tissue, the expression of miR-375 and miR-204 decreased, whereas the expression of miR-196a was significantly elevated. In OSCC, HOXB8 and p27 (CDKN1B) were the direct target genes of miR-196a, whereas HMGA2 was the direct target gene of miR-204. HOXB8 and p27 (CDKN1B) protein expression levels were inhibited by miR-196a, whereas the protein expression level of HMGA2 was inhibited by miR-204. Furthermore, the miR-196a inhibitor blocked cell proliferation. Our results indicate that the combined expression signatures of miR-375,
\end{abstract}

Correspondence to: Dr Jai-Sing Yang, Department of Medical Research, China Medical University Hospital, China Medical University, No. 2 Yuh-Der Road, Taichung 40447, Taiwan, R.O.C.

E-mail: jaisingyang@gmail.com

Key words: microRNA, miR-375, miR-204, miR-196a, oral cancer patients
miR-204 and miR-196a are promising biomarkers for the diagnosis, prognosis and treatment of OSCC.

\section{Introduction}

Worldwide, approximately $4 \%$ of all oral squamous cell carcinomas occur in men, with an increased frequency in males over the age of 50; geographical variations also affect the incidence of disease (1). Multiple gene changes accumulate as cell transition from normal cells into cancer cells during a multi-step process that includes changes in oncogenes and tumor suppressor genes. Many carcinogens and other factors are related to OSCC, including the use of tobacco and alcohol, which are the most important risk factors for head and neck cancers (2-4). Chewing betel quid is another primary risk factor for OSCC (5), and 85\% of all patients with OSCC chew betel quid on a regular basis (6). Betel quid contains artificial supplements such as arecoline and other alkaloids, which are carcinogenic.

New strategies to detect the early stages of OSCC are an essential and emergent issue. Several studies have focused on gene expression profiles, using cDNA microarrays to reveal genetic alterations in OSCC patients. Comparing aberrant miRNA expression profiles with matched normal controls in tissues and cell lines are beginning to unveil the mechanisms of OSCC disease progression (7). There is an increasing number of studies that analyze miRNA expression profiles in several cancers, and differentially expressed miRNAs are involved in the development of many malignancies, including OSCC $(8,9)$.

MicroRNAs (miRNAs) are 21-23 nucleotides long and inhibit protein synthesis (10) or cause mRNA degradation. Recent evidence has demonstrated that there are distinct microRNA expression signatures between tumor tissues and their normal counterparts, and it seems that miRNAs function as either oncogenes or tumor suppressors (11). Therefore, in the present study, we survey miRNA expression profiles and identify specific miRNA signatures by comparing normal and tumor tissues in patients with OSCC using a combination of miRNA microarray data mining with bioinformatics. These data can profoundly impact the development of clinically relevant diagnostic tools for the treatment of oral cancers. 


\section{Materials and methods}

Chemicals and reagents. Pre-miR ${ }^{\mathrm{TM}}$ precursors, Anti-miR ${ }^{\mathrm{TM}}$ inhibitors, siPORT ${ }^{\mathrm{TM}}$ NeoFX $^{\mathrm{TM}}$ reagents and the miRNA expression reporter vector were purchased from Applied Biosystems (Foster City, CA, USA).

Patients and tissue samples. The present study was reviewed and approved by an Institutional Review Board (IRB) at the China Medical University Hospital (CMUH IRB no. DMR98-IRB-202), Taichung, Taiwan (CMUH). After acquiring informed consent from each patient in the study at the Department of Otolaryngology, China Medical University Hospital (CMUH, Taichung, Taiwan), paired normal and tumor samples, mostly obtained from the tongue and other areas of the mouth, were collected from 39 patients who presented with primary OSCC. All tissues were frozen in liquid nitrogen immediately after surgery and stored at $-80^{\circ} \mathrm{C}$ until the extraction of RNA. The control group consisted of patients who obtained surgery for non-neoplastic diseases of the head and neck. Histological studies were also performed at the Department of Pathology in CMUH, and all tumors were confirmed as squamous cell carcinoma.

MicroRNA arrays. RNA samples were extracted and isolated using TRIzol reagent (Invitrogen, Carlsbad, CA, USA) and performed according to the manufacturer's instructions. One microgram of RNA was prepared for microarray analysis. The expression profiles of 365 mature miRNAs were assessed using TaqMan Human MicroRNA Arrays v2.0 (Applied Biosystems) according to the manufacturer's instructions.

Quantification of microRNA expression. TaqMan miRNA assays (Applied Biosystems) quantified the maturity of the miRNA samples from miR-375, miR-204 and miR-196a. RNU6B was the reference gene control. Quantitative polymerase chain reaction assays were performed according to the manufacturer's protocol. Briefly, RNA samples were reverse transcribed into specific cDNA; these specific cDNAs were quantified according to the manufacturer's instructions. All amplification reactions were performed in triplicate. The threshold cycle $(\mathrm{Ct})$ values were obtained and analyzed using the ABI 7900HT SDS 2.2 software.

Predicting microRNA target genes. Several computer software programs, including miRBase (http://microrna.sanger.ac.uk/), TargetScan (http://www.targetscan.org/), and miRanda (http:// www.microrna.org/), were used to analyze and compare potential microRNA target genes.

Cell culture. Oral cancer cell lines including CAL27 and HSC-3 were cultured in Dulbecco's modified Eagle's medium and Dulbecco's modified Eagle's medium/F-12 (Invitrogen), respectively. The media were supplemented with $10 \%$ heat-inactivated fetal bovine serum (FBS), 100 Units/ml penicillin and $100 \mu \mathrm{g} / \mathrm{ml}$ streptomycin (Invitrogen) (12).

miRNA transfection. miRNA transfection was performed using the NeoFX ${ }^{\mathrm{TM}}$ reagent according to the manufacturer's instructions (Applied Biosystems). Briefly, CAL27 cells were seeded onto 6-well plates and transfected with a $10 \mathrm{nM}$ solution of pre-miR-375, pre-miR-204, pre-miR-196a or pre-miR, which were used as control oligonucleotides (Applied Biosystems) for $48 \mathrm{~h}$.

Vector construction and luciferase reporter gene assays. Oligonucleotides for the potential target genes, miR-375, miR-204 and miR-196a, were cloned into a pMIR-Report vector (Applied Biosystems). The putative miR-375, miR-204 and miR-196a binding sites were cloned into the same vector and used as controls. Using jetSI-ENDO reagents (PolyPlus Transfection, Illkirch, France) in a luciferase reporter assay, CAL27 cells were co-transfected with $1.5 \mathrm{mg}$ of a pMIR-Report firefly luciferase construct, and $500 \mathrm{ng}$ of a pRL-CMV Renilla luciferase was used as a normalised control (Promega, Madison, WI, USA). In the presence of microRNA precursors and after $48 \mathrm{~h}$ of transfection, the luciferase activities were analyzed using a Dual-Luciferase reporter assay system (Promega, Madison, WI, USA) according to the manufacturer's instructions. All experiments were performed twice and repeated in three independent experiments (13).

Western blot analysis. Western blot analysis was carried out as previously described (14-16). Briefly, $30 \mu \mathrm{g}$ of protein was separated using a 10\% SDS-polyacrylamide gel and transferred onto polyvinylidene difluoride (PVDF) membranes (Millipore, Billerica, MA, USA). The membranes were incubated with a specific primary antibody overnight and then incubated with secondary antibody for $1 \mathrm{~h}$ at room temperature. Bands were detected using a commercially enhanced chemiluminescence system (GE Healthcare Biosciences, Piscataway, NJ, USA). The band intensities were analyzed using Adobe Photoshop software.

Stable miR-196a knockdown clones. HSC-3 human oral cancer cells $\left(3 \times 10^{5} /\right.$ well $)$ were seeded onto 6 -well plates overnight. Transfection was performed using Arrest-In reagents following the manufacturer's protocol (Thermo Fisher Scientific-Open Biosystems, Huntsville, AL, USA). Specific miR-196a knockdown stable clones were selected using $2.5 \mu \mathrm{g} / \mathrm{ml}$ of puromycin and were identified by western blot analysis.

Cell proliferation assay. HSC-3 cells or miR-196a knockdown HSC-3 cells were seeded onto 6-well plates at a density of $2 \times 10^{5}$ cells. Cells were trypsinized and counted every $24 \mathrm{~h}$. Cell proliferation assays were measured in triplicate using the Beckman Coulter Z1 Particle Counter $(17,18)$.

Statistical analysis. All data were expressed as the mean \pm standard deviations (SD). Differences between the groups were examined using the two-tailed unpaired Student's t-tests and an analysis of variance for the repeated measurements. Statistical significance between the groups was determined based on $\mathrm{P}$-values set at $\mathrm{P}<0.05$ (19).

\section{Results}

Validation of miR-375, miR-204 and miR-196a expression in 39 pairs of oral cancer patients. The 384-well TaqMan Human MicroRNA array screened and analysed the miRNA expression 
Table I. Upregulated miRNAs in oral cancer patients after analyzing by TaqMan ${ }^{\circledR}$ Human MicroRNA array.

\begin{tabular}{|c|c|c|}
\hline & Patient 1 stage IV & Patient 2 stage IV \\
\hline miRNA & $\begin{array}{c}\text { Fold change } \\
\text { (tumor vs. normal) }\end{array}$ & $\begin{array}{c}\text { Fold change } \\
\text { (tumor vs. normal) }\end{array}$ \\
\hline hsa-miR-196a & 66.13 & 19.66 \\
\hline hsa-miR-424 & 11.91 & 9.21 \\
\hline hsa-miR-517b & 10.13 & 11.29 \\
\hline hsa-miR-34c & 6.46 & 37.37 \\
\hline hsa-miR-21 & 5.72 & 5.7 \\
\hline hsa-miR-503 & 20.1 & 4.76 \\
\hline hsa-miR-644 & 17.83 & 4.88 \\
\hline hsa-miR-432 & 14.62 & 4.73 \\
\hline hsa-miR-618 & 8.65 & 2.36 \\
\hline hsa-miR-221 & 8.12 & 3.51 \\
\hline hsa-miR-31 & 8.12 & 2.75 \\
\hline hsa-miR-490 & 7.42 & 3.57 \\
\hline hsa-miR-196b & 5.61 & 3.07 \\
\hline hsa-miR-452 & 5.43 & 3.84 \\
\hline hsa-miR-222 & 4.75 & 2.25 \\
\hline hsa-miR-301 & 4.39 & 3.28 \\
\hline hsa-miR-130b & 4.06 & 3.57 \\
\hline hsa-miR-576 & 3.91 & 2.18 \\
\hline hsa-miR-556 & 3.66 & 4.82 \\
\hline hsa-miR-512-3p & 3.36 & 41.72 \\
\hline hsa-miR-18a & 3.17 & 5.09 \\
\hline hsa-miR-181d & 3.07 & 2.49 \\
\hline hsa-miR-324-5p & 2.92 & 3.19 \\
\hline hsa-miR-520h & 2.75 & 38.03 \\
\hline hsa-miR-34b & 2.62 & 4.99 \\
\hline hsa-miR-193b & 2.33 & 2.53 \\
\hline hsa-miR-365 & 2.31 & 2.33 \\
\hline hsa-miR-15b & 2.12 & 2.63 \\
\hline hsa-miR-450 & 2 & 19.4 \\
\hline
\end{tabular}

The 29 miRNAs were upregulated in oral cancer patients after miRNA expression was normalized with RNU44.

profiles for 2 patients. The miRNA expression profiles for OSCCs were compared with those in normal tissue. We found that 29 miRNAs were significantly upregulated (Table I), whereas 34 miRNAs were downregulated in these oral cancer patients (Table II). In Fig. 1, for example, the top 5 upregulated miRNAs of 2 patients were miR-196a, miR-424, miR-517b, miR-34c and miR-21, whereas the top 5 downregulated miRNAs were miR-375, miR-204, miR-433, miR-489 and miR-376a. In addition, although 218 miRNAs remained the same, 72 miRNAs were differentially expressed in oral cancer tissue.

Thirty-nine oral cancer patients were examined to determine whether the observed miRNA expression profiling was specific to the individual. Patients were classified into four groups: group I patients possessed tumor sizes $\leq 4 \mathrm{~cm}$ without metastasis; group II patients possessed tumor sizes $>4 \mathrm{~cm}$
Table II. Downregulated miRNAs in oral cancer patients after analyzing by TaqMan ${ }^{\circledR}$ Human MicroRNA array.

\begin{tabular}{|c|c|c|}
\hline & Patient 1 stage IV & Patient 2 stage IV \\
\hline miRNA & $\begin{array}{c}\text { Fold change } \\
\text { (tumor vs. normal) }\end{array}$ & $\begin{array}{c}\text { Fold change } \\
\text { (tumor vs. normal) }\end{array}$ \\
\hline hsa-miR-379 & 0.47 & 0.44 \\
\hline hsa-miR-656 & 0.44 & 0.07 \\
\hline hsa-miR-432 & 0.39 & 0.23 \\
\hline hsa-miR-554 & 0.39 & 0.06 \\
\hline hsa-miR-506 & 0.39 & 0.03 \\
\hline hsa-miR-100 & 0.37 & 0.12 \\
\hline hsa-miR-20b & 0.35 & 0.34 \\
\hline hsa-miR-195 & 0.34 & 0.28 \\
\hline hsa-miR-27b & 0.33 & 0.38 \\
\hline hsa-miR-125b & 0.33 & 0.22 \\
\hline hsa-miR-410 & 0.32 & 0.36 \\
\hline hsa-miR-99a & 0.32 & 0.09 \\
\hline hsa-miR-26a & 0.28 & 0.43 \\
\hline hsa-miR-218 & 0.27 & 0.15 \\
\hline hsa-miR-127 & 0.26 & 0.27 \\
\hline hsa-miR-369-5p & 0.26 & 0.25 \\
\hline hsa-miR-485-5p & 0.25 & 0.24 \\
\hline hsa-miR-328 & 0.23 & 0.29 \\
\hline hsa-miR-411 & 0.23 & 0.25 \\
\hline hsa-let-7c & 0.23 & 0.05 \\
\hline hsa-miR-149 & 0.22 & 0.22 \\
\hline hsa-miR-296 & 0.2 & 0.28 \\
\hline hsa-miR-126 & 0.18 & 0.4 \\
\hline hsa-miR-30a-3p & 0.17 & 0.4 \\
\hline hsa-miR-139 & 0.17 & 0.23 \\
\hline hsa-miR-487b & 0.13 & 0.42 \\
\hline hsa-miR-95 & 0.09 & 0.32 \\
\hline hsa-miR-486 & 0.09 & 0.27 \\
\hline hsa-miR-9 & 0.04 & 0.33 \\
\hline hsa-miR-376a & 0.19 & 0.19 \\
\hline hsa-miR-489 & 0.17 & 0.18 \\
\hline hsa-miR-433 & 0.14 & 0.2 \\
\hline hsa-miR-204 & 0.01 & 0.02 \\
\hline hsa-miR-375 & $<0.01$ & 0.02 \\
\hline
\end{tabular}

The 34 miRNAs were downregulated in oral cancer patients after miRNA expression was normalized with RNU44.

without metastasis; patients with tumor sizes $<4 \mathrm{~cm}$ who presented with metastasis belonged to group III; and patients possessing tumor sizes $>4 \mathrm{~cm}$ who presented with metastasis belonged to group IV (Table III). Indeed, miR-375 (Fig. 2A) and miR-204 (Fig. 2B) expression levels were significantly low in oral cancer patients. In contrast, miR-196a expression was dramatically increased in oral cancer patients (Fig. 2C). These data suggest that the expression levels of miR-375, miR-204 and miR-196a are good indicators of oral cancer progression. In addition, after analysing the clinical pathological 


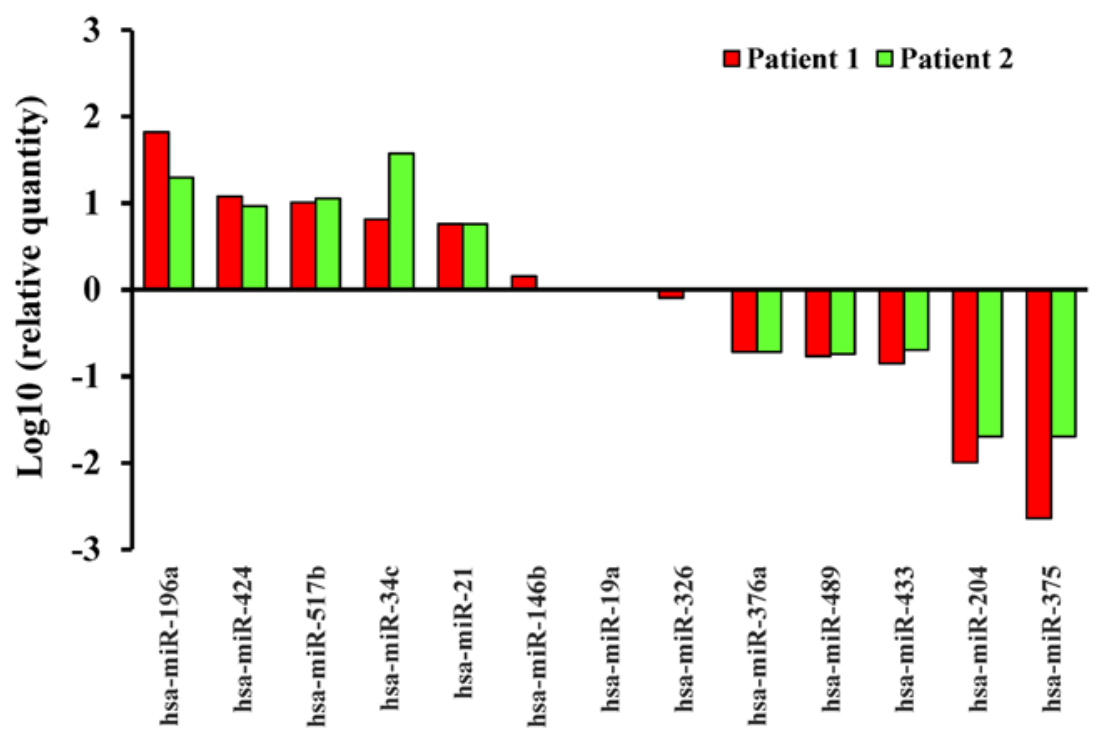

Figure 1. The miRNA expression profiling. Top five upregulated or downregulated miRNAs in two oral cancer patients. Differential miRNAs expression levels in the OSCC patient tumor tissue were compared with the patient normal tissue. The y-axis shows the ratio of miRNA expression of tumor/ normal on the scale of the log to the base 10 .

Table III. Patient demographics and clinicopathological characteristics $(\mathrm{N}=39)$.

\begin{tabular}{|c|c|c|c|c|}
\hline Stage & Early (I, II) & Late (III, IV) & Early (I, II) and metastasis & Late (III, IV) and metastasis \\
\hline Female & 1 & 0 & 0 & 2 \\
\hline Male & 21 & 3 & 5 & 7 \\
\hline Age (years) & $33-67$ & $28-50$ & $41-57$ & $32-74$ \\
\hline Smoking & $18(82 \%)$ & $2(67 \%)$ & $4(80 \%)$ & $7(78 \%)$ \\
\hline Chewing betel & $17(77 \%)$ & $2(67 \%)$ & $2(40 \%)$ & $6(67 \%)$ \\
\hline Tumor site & SCC & $\mathrm{SCC}$ & SCC & SCC \\
\hline
\end{tabular}

SCC, squamous cell carcinoma.

characteristics of 39 patients, we found that $>67 \%$ of the patients were habitual smokers and chewed betel quid, which are both risk factors for OSCC in Taiwan (Table III).

Targeted prediction and Gene Ontology analysis for miR-375, miR-204 and miR-196a. The combined use of different computer software programs helped predict the target genes of miRNAs (miR-375, miR-204 and miR-196a) (Table IV). The HSPA12A, INSM1, MTPN, PDK1, UBE2E and USP1 were potential miR-375 gene targets and are associated with the development of oral cancers (20). Specifically, previous studies have demonstrated that PDPK1 and MTPN are miR-375 gene targets in pancreatic cancer $(21,22)$. Bcl-2, FJX1, HMGA2, MEIS1, RAB1A and SOX4 are potential target genes for miR-204 and have been associated with cancer development using similar approaches $(23,24)$. Lastly, the potential target genes in miR-196 were ANXA1, p27 (CDKN1B), HOXB8, HOXC8, ING5 and LRP1B, which are associated with the development of oral cancers (25-27).

Validation of miR-375, miR-204 and miR-196a targeted genes using luciferase reporter assays. Constructs of miRNA target genes were introduced into a 3'UTR miRNA luciferase gene in an expression reporter vector. The CAL27 cells were transfected with the luciferase reporter gene plasmid either in the presence or absence of a miR-375 precursor. There was no change in inhibition for the luciferase activity in 6 potential miR-375 target genes (Fig. 3A). Unexpectedly, MTPN and PDK1 are target genes for miR-375 in pancreatic cancer $(22,28)$, but not in oral cancers. The luciferase activity from 6 potential miR-204 target genes decreased dramatically, including HMGA2 (Fig. 3B) in CAL27 cells. Furthermore, the luciferase activity from 6 potential miR196a target genes was dramatically inhibited, especially in HOXB8 and p27 (CDKN1B) (Fig. 3C).

Characterisation of $\mathrm{miR}-375, \mathrm{miR}-204$ and $\mathrm{miR}-196 \mathrm{a}$ targeted genes using western blot analysis. CAL27 cells were transfected with or without a miR-375 precursor to detect PDK1 protein expression levels. In previous studies, the concentration of glucose affected PDK1 protein expression levels (22). Our results, however, indicate that the expression level remained the same regardless of the glucose concentrations added to CAL27 (Fig. 4A). Thus, PDK1 may 


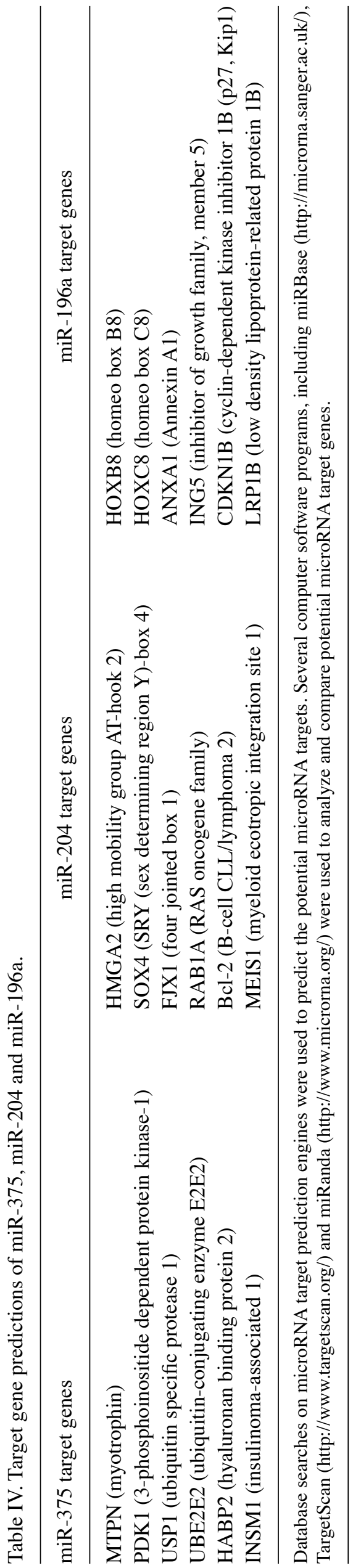

$\mathbf{A}$

$\operatorname{miR}-375$

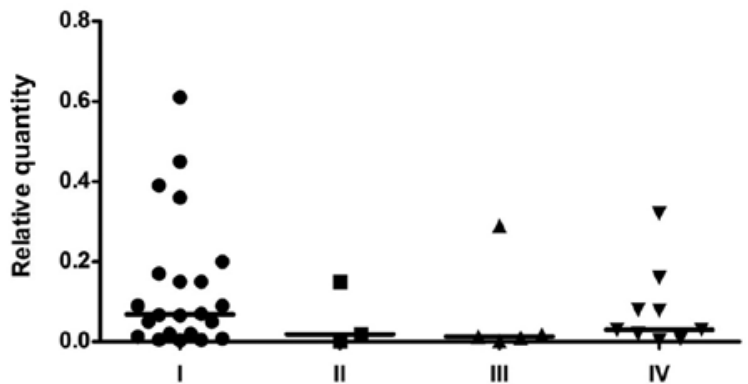

\begin{tabular}{|c|c|c|c|c|}
\hline Average & 0.0685 & 0.0190 & 0.0130 & 0.0300 \\
\hline$P$-values & $<0.01$ & $<0.01$ & $<0.01$ & $<0.01$ \\
\hline
\end{tabular}

B

miR-204

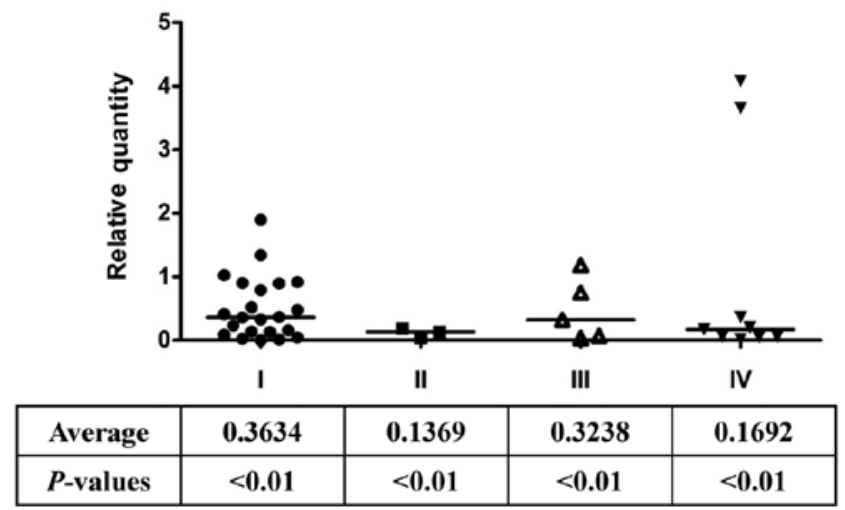

C

miR-196a

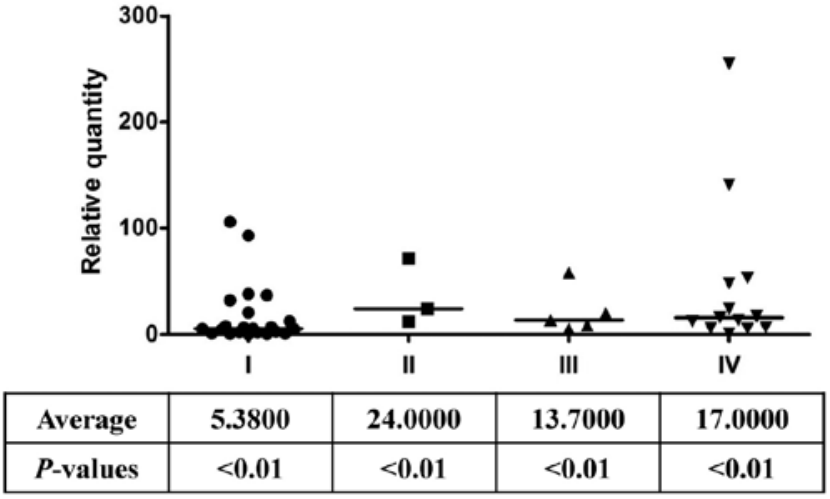

Figure 2. The miR-375, miR-204 and miR-196a expression profiling in 39 OSCC patients. Differential miRNA expression levels in OSCC patient tumor tissues were compared with normal tissues. The qRT-PCR was used to analyze the expression of (A) miR-375, (B) miR-204 and (C) miR-196a in 39 pairs of oral cancer patients. Patients were classified into four groups. The $y$-axis shows the ratio of miRNA expression in tumor vs. normal tissue. The miRNA expression fold changes were normalized using RNU6B. $\mathrm{P}<0.01$ was considered significantly different compared with the control group.

not be the miR-375 targeted gene in oral cancers. Recently, KLF5 was found to be regulated by miR-375 (29). We examined the protein expression level of KLF5 in the presence of a miR-375 inhibitor. Indeed, inhibition of miR-375 caused the upregulation of KLF5 in CAL27 (Fig. 4B). Next, the protein expression level of HMGA2 was examined in the presence of a miR-204 precursor. As predicted, the protein 

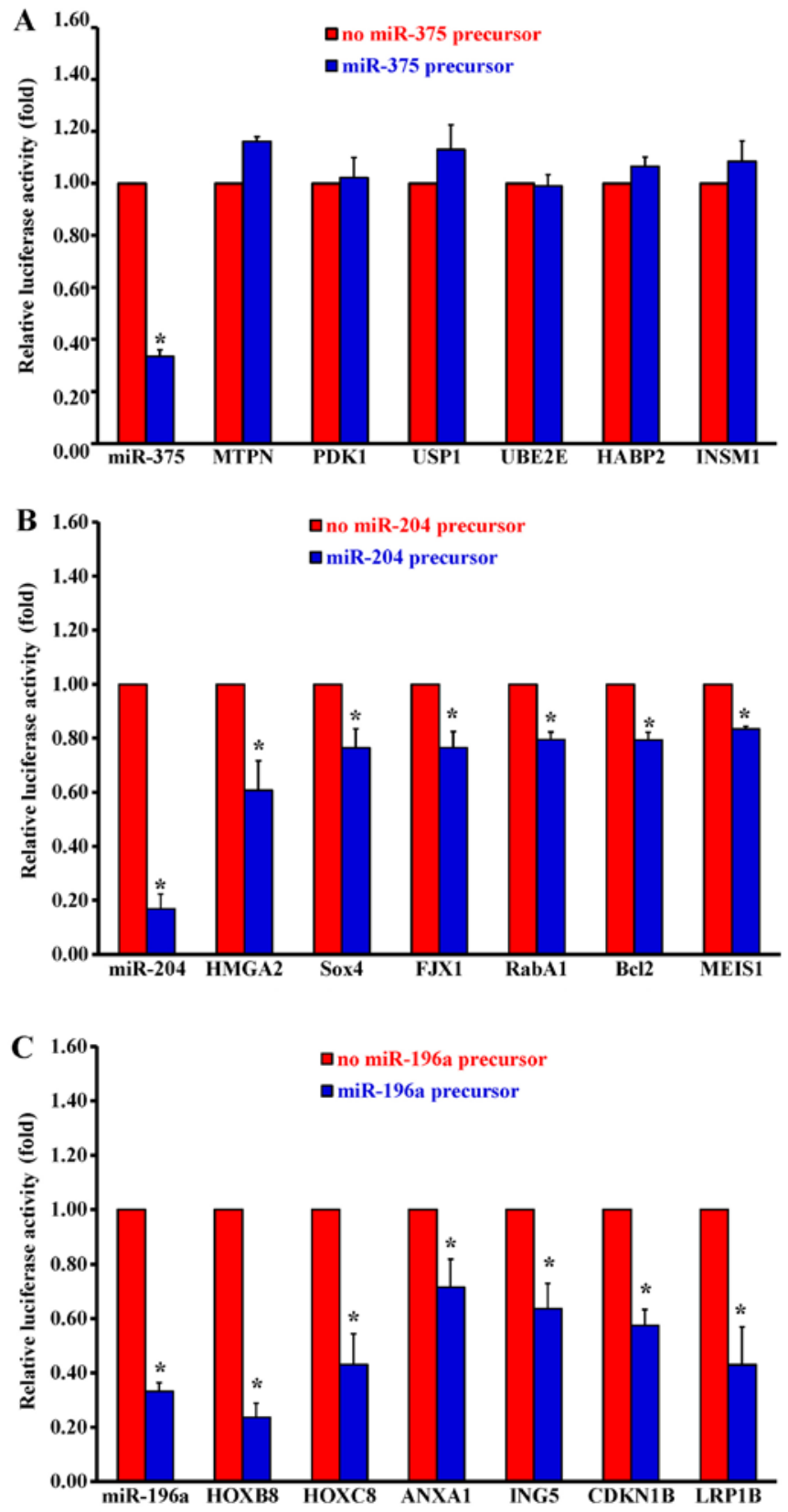

Figure 3. Predicted target genes for deregulated miRNAs in CAL27 cells using the luciferase reporter assay. The relative luciferase expression levels of 3'UTR reporter constructs transfected with synthetic precursors of (A) miR-375, (B) miR-204 and (C) miR-196a were compared with a scrambled negative control. The pMIR-REPORT ${ }^{\mathrm{TM}}$ luciferase and microRNA precursors were co-transfected into CAL27 cells for $48 \mathrm{~h}$. The cells were harvested for use in the luciferase activity assay. The data are presented as the mean \pm SD of three independent experiments. ${ }^{*} \mathrm{P}<0.05$, significantly different compared with the control group.

expression levels of HMGA2 were significantly inhibited by the miR-204 precursor. These results suggest that HMGA2 is one of the miR-204 directly targeted genes (Fig. 4C). In addition, the protein expression levels of HOXB8 and p27 (CDKN1B) were also examined in the presence of a miR196a inhibitor. As predicted, the protein expression levels of HOXB8 and p27 (CDKN1B) were significantly increased by the miR-196a inhibitor, suggesting that HOXB8 and p27 (CDKN1B) are two genes that are directly targeted by miR-196a (Fig. 4D).

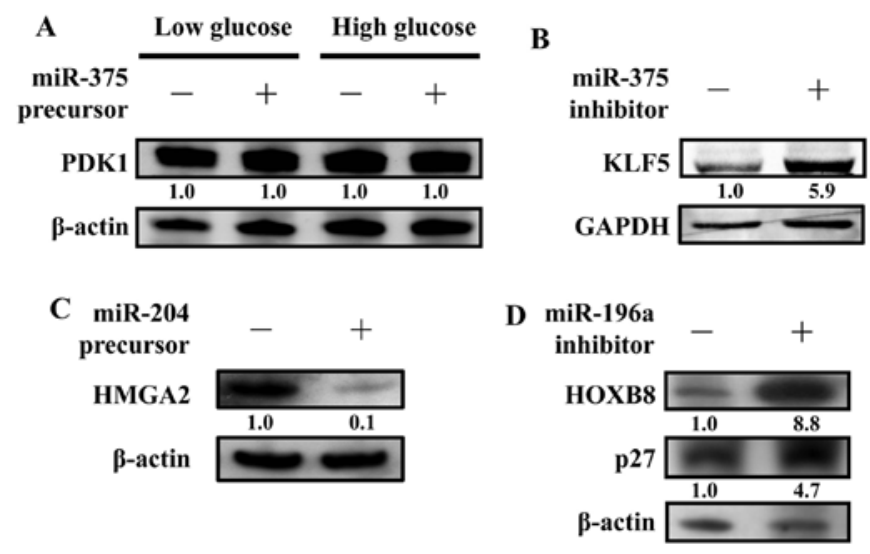

Figure 4. Verification of deregulated miRNA functions. Predicted target genes of deregulated miRNAs using western blot analyses. The CAL27 cells were cultured in the absence or presence of (A) the miR-375 precursor, (B) miR-375 inhibitor, (C) the miR-204 precursor and (D) the miR-196a inhibitor for $48 \mathrm{~h}$. The cell lysates were performed using western blot analyses as indicated.

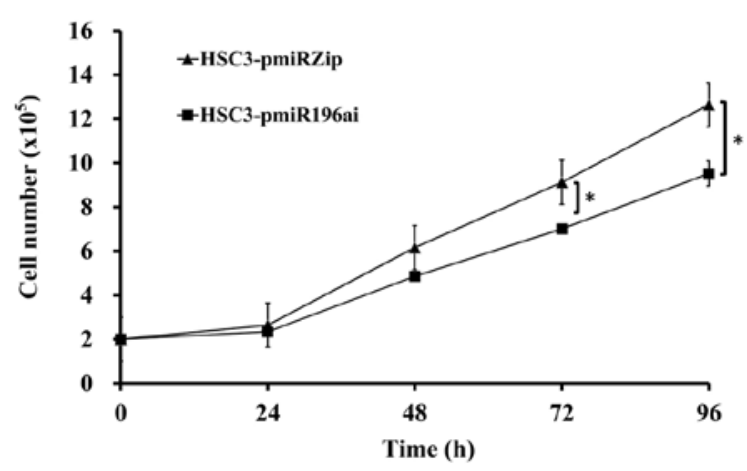

Figure 5. miR-196a inhibits cell proliferation. HSC3 knockdown miR-196a (HSC3-pmiR-196ai) cells and HSC3-pmiRZIP control cells were seeded with $2 \times 10^{5} /$ well into a 6 -well plate. Cells were counted every $24 \mathrm{~h}$.

miR-196a knockdown cells reduces cell proliferation. HSC3 cells were transfected with either the pmiRZIP vector only or pmiRZIP-miR-196a. After 48-h transfection, cells were cultured in the medium containing $2.5 \mu \mathrm{g} / \mathrm{ml}$ and medium was changed every 3 days until a single clone formed. HSC3 knockdown miR-196a (HSC3-pmiR-196ai) cells and the control HSC3-pmiRZIP cells were seeded with $2 \times 10^{5} /$ well into a 6-well plate. Cells were counted every $24 \mathrm{~h}$. Indeed, HSC3-pmiR-196ai cells grow slower than control HSC3 cells (Fig. 5).

\section{Discussion}

To date, several published studies have addressed the differential expression of miRNAs in oral cancers. However, a comprehensive analysis of miRNA-targeted genes could lead to the elucidation of pathways that could deregulate cancer cells and subsequently identify therapeutic targets. In the present study, the expression levels of 365 microRNAs were investigated in OSCC. After validation by quantitative reverse transcription-PCR, we discovered that miR-375 and miR-204 were downregulated, whereas miR-196a was upregulated (Fig. 1 and Tables I and II). The downregulation 


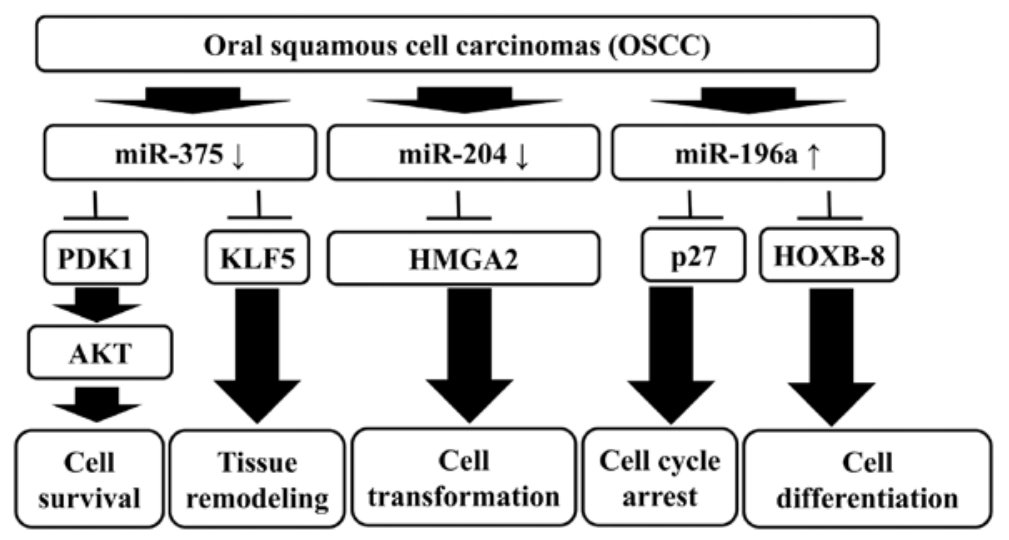

Figure 6. A proposed model for the function of differential miRNA expression in oral squamous cell carcinomas.

of miR-375 in HNSCC tumors is consistent with previous findings that miR-375 is expressed at significantly greater levels in laryngeal tumors compared with those in the oral cavity (Fig. 2A). The elevated expression of miR-375 is significantly associated with alcohol consumption (30). Notably, 3-phosphoinositide-dependent protein kinase 1 (PDK1) is a kinase that activates anti-apoptotic AKT. However, our data did not show any change in the protein expression levels of PDK1 (Fig. 4A).

Several lines of evidence have demonstrated that miR-204 is responsible for different expression patterns in cancer. Overexpression of miR-204, for example, is correlated with insulinomas (31). In contrast, the downregulation of miR-204 targets HOXA10 and MEIS1 in acute myeloid leukaemia (32). The data presented here show that miR-204 is downregulated in oral cancers and in the high mobility group A2 (HMGA2) gene, which is one of its direct targets (Figs. 2B, 3B and 4C). In addition, miR-196a was highly expressed in oral cancers, and HOXB8 (homeobox B8) is one of the potential target genes of miR-196a (Figs. 2C, 3C and 4D). Thus, our results are consistent with previous studies (33). HOXB8, located on chromosome 17 , is one of the homeobox gene family members and is involved in development. Furthermore, several studies have shown that aberrant HOXB8 expression is correlated with cancer formation. Elevated expression of HOXB8, for example, is associated with colorectal cancer (34). Additionally, HOXB8 has been identified as a cause of leukaemia, and it regulates smooth muscle cell differentiation. It is speculated that abnormal HOXB8 expression leads to tumorigenesis in OSCC (35). Here, we demonstrated that HOXB8 expression is reduced via miR-196a suppression. It is important to understand the role that HOXB8-mediated molecular mechanisms play in the development of oral cancers. Moreover, p27 (CDKN1B), a cyclin-dependent kinase (Cdk) inhibitor, may be another potential target of miR-196a, which functions as a negative cell cycle regulator. It was demonstrated that $\mathrm{p} 27$ (CDKN1B) was downregulated and is strongly associated with various cancers, including OSCC (36) (Fig. 4D). HSC3 cells were either individually transfected with the pmiRZIP vector or with pmiRZIP-miR-196a. After a 48-h transfection, the cells were cultured in a medium containing $2.5 \mu \mathrm{g} / \mathrm{ml}$; the medium was changed every 3 days until a single clone formed. An HSC3 knockdown of miR-196a (HSC3-pmiR-196ai) cells and the control HSC3-pmiRZIP cells were counted every $24 \mathrm{~h}$. It was observed that the HSC3-pmiR-196ai cells grew slower than the control HSC3 cells (data not shown).

Overall, this study provides evidence that miRNA signature profiling is a potential diagnostic tool and therapy to target cancer. Furthermore, the characterization of miRNA profiling provides new insights into the pathogenesis and progression of OSCC. Although the underlying biological mechanisms of miRNAs remain largely unknown, there is compelling evidence that miRNAs will advance the management of OSCC in the near future (37). Our results suggest that miR-375, miR-204 and miR-196a are differentially expressed in OSCC, and the combined expression signatures of miR-375, miR-204 and miR-196a provide promising biomarkers for the diagnosis, prognosis and therapeutic utility of OSCC clinical treatment (Fig. 6).

\section{Acknowledgements}

The present study was supported in part by a grant from the China Medical University (CMU95-305) and in part by a grant from the National Science Council (NSC 98-2815-C-039016-B). We thank Jian-Chiao Wang and the lab members in Drs Tsai and Kao for their suggestions during this study.

\section{References}

1. Warnakulasuriya S: Global epidemiology of oral and oropharyngeal cancer. Oral Oncol 45: 309-316, 2009.

2. Camisasca DR, Silami MA, Honorato J, Dias FL, de Faria PA and Lourenço SQ: Oral squamous cell carcinoma: Clinicopathological features in patients with and without recurrence. ORL J Otorhinolaryngol Relat Spec 73: 170-176, 2011.

3. Chang CH, Lee CY, Lu CC, Tsai FJ, Hsu YM, Tsao JW, Juan YN, Chiu HY, Yang JS and Wang CC: Resveratrol-induced autophagy and apoptosis in cisplatin-resistant human oral cancer CAR cells: A key role of AMPK and Akt/mTOR signaling. Int J Oncol 50: 873-882, 2017.

4. Yuan CH, Horng CT, Lee CF, Chiang NN, Tsai FJ, Lu CC, Chiang JH, Hsu YM, Yang JS and Chen FA: Epigallocatechin gallate sensitizes cisplatin-resistant oral cancer CAR cell apoptosis and autophagy through stimulating AKT/STAT3 pathway and suppressing multidrug resistance 1 signaling. Environ Toxicol 32: 845-855, 2017.

5. Tovosia S, Chen PH, Ko AM, Tu HP, Tsai PC and Ko YC: Prevalence and associated factors of betel quid use in the Solomon Islands: A hyperendemic area for oral and pharyngeal cancer. Am J Trop Med Hyg 77: 586-590, 2007. 
6. Chiang SL, Jiang SS, Wang YJ, Chiang HC, Chen PH, Tu HP, Ho KY, Tsai YS, Chang IS and Ko YC: Characterization of arecoline-induced effects on cytotoxicity in normal human gingival fibroblasts by global gene expression profiling. Toxicol Sci 100: 66-74, 2007.

7. Chang SS, Jiang WW, Smith I, Poeta LM, Begum S, Glazer C, Shan S, Westra W, Sidransky D and Califano JA: MicroRNA alterations in head and neck squamous cell carcinoma. Int J Cancer 123: 2791-2797, 2008.

8. Scapoli L, Palmieri A, Lo Muzio L, Pezzetti F, Rubini C, Girardi A, Farinella F, Mazzotta M and Carinci F: MicroRNA expression profiling of oral carcinoma identifies new markers of tumor progression. Int J Immunopathol Pharmacol 23 $1229-1234,2010$

9. Gorenchtein M, Poh CF, Saini R and Garnis C: MicroRNAs in an oral cancer context - from basic biology to clinical utility. J Dent Res 91: 440-446, 2011.

10. Ambros V: The functions of animal microRNAs. Nature 431: 350-355, 2004

11. Hammond SM: MicroRNAs as oncogenes. Curr Opin Genet Dev 16: 4-9, 2006.

12. Yu FS, Yang JS, Yu CS, Lu CC, Chiang JH, Lin CW and Chung JG: Safrole induces apoptosis in human oral cancer HSC-3 cells. J Dent Res 90: 168-174, 2011.

13. Tsai SC and Seto E: Regulation of histone deacetylase 2 by protein kinase CK2. J Biol Chem 277: 31826-31833, 2002.

14. Tsai SC, Valkov N, Yang WM, Gump J, Sullivan D and Seto E: Histone deacetylase interacts directly with DNA topoisomerase II. Nat Genet 26: 349-353, 2000.

15. Huang WW, Chiu YJ, Fan MJ, Lu HF, Yeh HF, Li KH, Chen PY, Chung JG and Yang JS: Kaempferol induced apoptosis via endoplasmic reticulum stress and mitochondria-dependent pathway in human osteosarcoma U-2 OS cells. Mol Nutr Food Res 54: $1585-1595,2010$

16. Huang SH, Wu LW, Huang AC, Yu CC, Lien JC, Huang YP, Yang JS, Yang JH, Hsiao YP, Wood WG, et al: Benzyl isothiocyanate (BITC) induces G2/M phase arrest and apoptosis in human melanoma A375.S2 cells through reactive oxygen species (ROS) and both mitochondria-dependent and death receptor-mediated multiple signaling pathways. J Agric Food Chem 60: 665-675, 2012.

17. Lai KC, Huang AC, Hsu SC, Kuo CL, Yang JS, Wu SH and Chung JG: Benzyl isothiocyanate (BITC) inhibits migration and invasion of human colon cancer HT29 cells by inhibiting matrix metalloproteinase-2/-9 and urokinase plasminogen (uPA) through PKC and MAPK signaling pathway. J Agric Food Chem 58: 2935-2942, 2010.

18. Liao CL, Lai KC, Huang AC, Yang JS, Lin JJ, Wu SH, Gibson Wood W, Lin JG and Chung JG: Gallic acid inhibits migration and invasion in human osteosarcoma U-2 OS cells through suppressing the matrix metalloproteinase-2/-9, protein kinase B (PKB) and PKC signaling pathways. Food Chem Toxicol 50: 1734-1740, 2012

19. Ma YS, Weng SW, Lin MW, Lu CC, Chiang JH, Yang JS, Lai KC, Lin JP, Tang NY, Lin JG, et al: Antitumor effects of emodin on LS1034 human colon cancer cells in vitro and in vivo: Roles of apoptotic cell death and LS1034 tumor xenografts model. Food Chem Toxicol 50: 1271-1278, 2012.

20. Kato H, Uzawa K, Onda T, Kato Y, Saito K, Nakashima D, Ogawara K, Bukawa H, Yokoe $\mathrm{H}$ and Tanzawa H: Downregulation of $1 \mathrm{D}$-myo-inositol 1,4,5-trisphosphate 3-kinase $\mathrm{A}$ protein expression in oral squamous cell carcinoma. Int J Oncol 28: 873-881, 2006.

21. Mello CC and Czech MP: Micromanaging insulin secretion. Nat Med 10: 1297-1298, 2004.
22. El Ouaamari A, Baroukh N, Martens GA, Lebrun P, Pipeleers D and van Obberghen E: miR-375 targets 3'-phosphoinositidedependent protein kinase-1 and regulates glucose-induced biological responses in pancreatic beta-cells. Diabetes 57: 2708-2717, 2008.

23. Conte I, Carrella S, Avellino R, Karali M, Marco-Ferreres R, Bovolenta P and Banfi S: miR-204 is required for lens and retinal development via Meis2 targeting. Proc Natl Acad Sci USA 107: 15491-15496, 2010.

24. Lee Y, Yang X, Huang Y, Fan H, Zhang Q, Wu Y, Li J, Hasina R, Cheng C, Lingen MW, et al: Network modeling identifies molecular functions targeted by miR-204 to suppress head and neck tumor metastasis. PLOS Comput Biol 6: e1000730, 2010.

25. Kim YJ, Bae SW, Yu SS, Bae YC and Jung JS: miR-196a regulates proliferation and osteogenic differentiation in mesenchymal stem cells derived from human adipose tissue. J Bone Miner Res 24: 816-825, 2009.

26. Luthra R, Singh RR, Luthra MG, Li YX, Hannah C, Romans AM, Barkoh BA, Chen SS, Ensor J, Maru DM, et al: MicroRNA-196a targets annexin A1: A microRNA-mediated mechanism of annexin A1 downregulation in cancers. Oncogene 27: 6667-6678, 2008.

27. Schimanski CC, Frerichs K, Rahman F, Berger M, Lang H, Galle PR, Moehler M and Gockel I: High miR-196a levels promote the oncogenic phenotype of colorectal cancer cells. World J Gastroenterol 15: 2089-2096, 2009.

28. Poy MN, Eliasson L, Krutzfeldt J, Kuwajima S, Ma X, Macdonald PE, Pfeffer S, Tuschl T, Rajewsky N, Rorsman P, et al: A pancreatic islet-specific microRNA regulates insulin secretion. Nature 432: 226-230, 2004.

29. Shi W, Yang J, Li S, Shan X, Liu X, Hua H, Zhao C, Feng Z, Cai Z, Zhang L, et al: Potential involvement of miR-375 in the premalignant progression of oral squamous cell carcinoma mediated via transcription factor KLF5. Oncotarget 6: 40172-40185, 2015.

30. Avissar M, McClean MD, Kelsey KT and Marsit CJ: MicroRNA expression in head and neck cancer associates with alcohol consumption and survival. Carcinogenesis 30: 2059-2063, 2009.

31. Roldo C, Missiaglia E, Hagan JP, Falconi M, Capelli P, Bersani S, Calin GA, Volinia S, Liu CG, Scarpa A, et al: MicroRNA expression abnormalities in pancreatic endocrine and acinar tumors are associated with distinctive pathologic features and clinical behavior. J Clin Oncol 24: 4677-4684, 2006.

32. Garzon R, Garofalo M, Martelli MP, Briesewitz R, Wang L, Fernandez-Cymering C, Volinia S, Liu CG, Schnittger S, Haferlach $\mathrm{T}$, et al: Distinctive microRNA signature of acute myeloid leukemia bearing cytoplasmic mutated nucleophosmin. Proc Natl Acad Sci USA 105: 3945-3950, 2008.

33. Yekta S, Shih IH and Bartel DP: MicroRNA-directed cleavage of HOXB8 mRNA. Science 304: 594-596, 2004.

34. Vider BZ, Zimber A, Hirsch D, Estlein D, Chastre E, Prevot S, Gespach C, Yaniv A and Gazit A: Human colorectal carcinogenesis is associated with deregulation of homeobox gene expression. Biochem Biophys Res Commun 232: 742-748, 1997.

35. Cheng AM, Byrom MW, Shelton J and Ford LP: Antisense inhibition of human miRNAs and indications for an involvement of miRNA in cell growth and apoptosis. Nucleic Acids Res 33: 1290-1297, 2005.

36. Kudo Y, Kitajima S, Ogawa I, Miyauchi M and Takata T: Downregulation of $\mathrm{Cdk}$ inhibitor p27 in oral squamous cell carcinoma. Oral Oncol 41: 105-116, 2005.

37. Wu BH, Xiong XP, Jia J and Zhang WF: MicroRNAs: New actors in the oral cancer scene. Oral Oncol 47: 314-319, 2011. 